\author{
Military Technical College \\ Kobry El-Kobbah, \\ Cairo, Egypt.
}

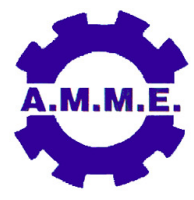

\author{
$16^{\text {th }}$ International Conference \\ on Applied Mechanics and \\ Mechanical Engineering.
}

\title{
MODIFICATION OF A SURFACE LAYER MICROSTRUCTURE FOR NODULAR CAST IRON USING $\mathrm{CO}_{2}$ LASER
}

\author{
H. F. El-Labban*
}

\begin{abstract}
Laser surface melting was used to produce a sound surface layer of modified and hard structure for a nodular cast iron. The high hardness of surface is an important requirement for the high wear resistance. The treatments were carried out using $\mathrm{CO} 2$ laser of $6 \mathrm{~kW}$. Nitrogen was used as a shielding gas. The effect of the processing power on the structure and hardness of the nodular cast iron have been studied. The microstructures of the treated zones and base metal were investigated using optical and scanning electron microscopes. Three main zones were resulted; the melted and solidified zone, hardened one (heat affected zone: HAZ) and the base metal. In the melted and solidified zone, high percentages of graphite nodules were completely dissolved and fine dendrites of austenite surrounded by cementite and some martensite were produced. Graphite nodules and martensitic structure have been observed in the HAZ. In the three conditions of treatment $(700,1000$ and $1500 \mathrm{~W}$ at beam travelling speed of $500 \mathrm{~mm} / \mathrm{min}$.), no cracks were observed in the two zones; melted and solidified zone and the HAZ. Remarkable improvements $(420-470 \%)$ in microhardness values for the melted and solidified layers were achieved. The depth of this zone is increased with the increase of processing power. The maximum melted depths for the hardest layers were $0.8,1.2$ and $1.4 \mathrm{~mm}$ in the cases of 700, 1000 and $1500 \mathrm{~W}$ respectively. HAZ of High hardness was also obtained.
\end{abstract}

\section{KEY WORDS}

Nodular iron, surface hardness, surface treatments, laser surface treatments, laser surface melting, microstructure modification.

\footnotetext{
* Associate Professor, Dept. of Production Engineering, Alexandria University, Alexandria, Egypt.
} 


\section{INTRODUCTION}

The nodular cast iron is used in many applications due to its good combination of strength and toughness, high fatigue endurance $[1,2]$, machinability, and relatively low cost [2]. However, it suffers from low wear resistance under severe service conditions [3, 4-7]. In these cases the worn components are replaced and as a result the cost is increased [8]. The applications of nodular cast iron can be widened by increasing the surface hardness and improving the wear resistance through a modification of a surface layer microstructure by using the traditional methods such as nitriding, boriding or thin film deposition. In these cases, the presence of graphite phases near the surface causes a weak adhesion between the hard layer and substrate material and consequently the failure can be accelerated [9]. In addition, graphite can act as a crack nucleation site under solid particle erosion. Also, graphitic corrosion can be occurred due to the corrosive atmosphere. To solve this problem, chilled cast process, TIG melting and energy beam processes (laser and electron beam) are recommended [9-12]. There are difficulties in application of chilled casting method for the castings of complex shapes. The cost of electron beam technology is high. Therefore, TIG melting and laser technology can be selected. However, laser surface melting produced extensive cracking of pearlitic nodular iron (SGP) due to the overall contribution of thermal stresses generated under high-energy density conditions [13]. Generally, the microstructures of surface and subsurface layers can be modified and consequently hardness and wear resistance can be improved by application of suitable laser surface treatments. The laser transformation hardening, laser surface melting and laser surface alloying are examples of these treatments. In case of laser transformation hardening, the graphite nodules are not completely dissolved in the treated zone. The laser surface alloying increases material cost and also increases the consumption of the alloying elements [14]. Laser surface melting (LSM) can be used to harden alloys that cannot be hardened by laser transformation hardening [15]. In laser surface melting, the metal surface is melted and rapidly solidified by self quenching [14]. For the effective treatment conditions, the resulted high cooling rates; (103-106 K/s); [15], can lead to refinement of the microstructure, extension of solid solubility and production of an amorphous structure or meta-stable phases [14]. As a result, the hardness can be improved [14].

Therefore, the present work has been planned to study the applicability of high power $\mathrm{CO}_{2}$ laser in surface melting for a nodular iron aiming to produce a sound and hard surface layer (melted and solidified zone without cracks) of modified microstructure without /or with minimum percentage of graphite nodules.

\section{EXPERIMENTAL WORK}

The nodular cast iron of chemical composition listed in Table 1 was used as a base metal. Components of small thickness; $6 \mathrm{~mm}$; and width; $50 \mathrm{~mm}$; from this material were used as specimens in this study. Laser surface melting was carried out using 6 $\mathrm{KW} \mathrm{CO}_{2}$ laser machine. The defocusing distance was $10 \mathrm{~mm}$. Shielding was performed using nitrogen under pressure of $0.5 \mathrm{bar}$ and flow rate of $27 \mathrm{l} / \mathrm{min}$. The process was done at powers of 700,1000 and $1500 \mathrm{~W}$ and beam travelling speed of 
Table 1. Chemical composition of the base metal (nodular cast iron of $6 \mathrm{~mm}$ thickness and $50 \mathrm{~mm}$ width).

\begin{tabular}{|c|c|c|c|c|c|c|c|}
\hline $\mathbf{C}$ & $\mathbf{S i}$ & $\mathbf{M n}$ & $\mathbf{P}$ & $\mathbf{S}$ & $\mathbf{M g}$ & $\mathbf{C u}$ & $\mathbf{F e}$ \\
\hline 3.82 & 2.7 & 0.237 & 0.02 & 0.014 & 0.05 & 0.02 & 93.03 \\
\hline
\end{tabular}

$500 \mathrm{~mm} / \mathrm{min}$. The effects of these conditions on microstructure and the hardness distribution through the thickness of specimens were studied. The microstructures of the treated zones and base metal were investigated using optical and scanning electron microscopes. The microhardness of treated zone and subsurface layers was evaluated using a microhardness tester.

\section{RESULTS AND DISCUSSIONS}

\section{Effect of Treatment on the Microstructure}

The microstructure of the base metal is shown in the optical micrographs and SEM images of Fig. 1. Graphite nodules surrounded by ferritic halo and pearlitic structure in the matrix are clearly observed in the microstructure of the nodular iron used as a base metal.

The macro- and micro-structures of the treated specimens were investigated using optical and scanning electron microscopes. Figures 2(a, b and c) are examples for the macrostructures of three specimens treated at three different powers; $700 \mathrm{~W}(\mathrm{a})$, $1000 \mathrm{~W}$ (b) and $1500 \mathrm{~W}$ (c). The width and depth of the melted zone (MZ), and also the width of the HAZ increase with the increase of laser power. This can be attributed to the increase of the heat input in the case of high power.

Three main zones were resulted; the melted zone (MZ), hardened one (heat affected zone: $\mathrm{HAZ}$ ) and the base metal (BM). The microstructures of the melted and solidified layer produced at three different powers (700, 1000 and $1500 \mathrm{~W}$ ) are shown in the figures 3, 4 and 5, respectively. In the three cases, high percentages of graphite nodules are completely dissolved, and new and fine dendritic structure consisting of retained austenite containing a high concentration of dissolved carbon, cementite and some martensite are produced. For the base and the melted zones, the different phases were analyzed with the aid of XRD. Figures 6 ( $a$ and $b$ ) show the results of these analyses. By comparing the $d$ spacing or the position angles of the peaks with the standard peaks for ferrite, martensite, austenite, and cementite, it is clear that untreated cast iron showed alpha iron as the dominant phase, cementite $\left(\mathrm{Fe}_{3} \mathrm{C}\right)$ and graphite. However, the melted surface layer showed peaks of cementite, martensite, grahite, austenite and traces of alpha iron. For more details, additional analyses using other methods (such as EPMA) are required. Similar results were obtained by other investigators for nodular iron surfaces melted by Nd-YAG laser [14]. In this zone, a layer is rapidly solidified by self-quenching. As a result and according to the principles reported by some investigators [15], the nucleation during solidification can be occurred with undercooling and consequently, refinement of the microstructure, extension of solid solubility and production of an amorphous structure 
or meta-stable phases can be obtained. Some partially dissolved graphite nodules are also found in the melted and solidified zone as shown in Fig. 4 (a). Similar results were obtained by other investigators [16], in which graphite nodules were found in a surface layer of the nodular cast iron melted by pulsed Nd: YAG laser and the reason was explained by the effect of both hydrodynamic forces and the buoyancy move towards the free surface.

To reduce (or eliminate) the crack nucleation site under solid particle erosion and the graphitic corrosion, the graphite nodules at and near the surface should be reduced or eliminated [9]. In this aspect, it is important to compare the effect of the present treatment (laser surface melting) with that of the chilled casting on the presence of graphite in a surface layer. In the present treatment, the graphite nodules in the melted layer were remarkably reduced while in the case of chilled casting, these nodules are not eliminated from the surface and the process led to ledeburite transformation of the iron matrix [9]. In case of chilled casting of GGG 40 (nodular cast iron) the constitution consisted of mixed phases such as martensite, pearlite, primer cementite and retained austenite [9]. In addition and as reviewed above, there are difficulties in application of chilled casting method for the castings of complex shapes [9-12]. However, in case of laser surface melting, the complex shapes can be easily treated. On the other hand and from the economical point of view, the chilling process is a preferable option as it can be applied during the casting process [9].

As shown in Fig. 7 (a), pores are found near the interface between the melted zone and the HAZ. During the treatment, combustion of graphite nodules can be resulted and consequently the graphite can be removed by the protecting gas. Similar observations at the outer surface of pearlitic ductile iron hardened by Nd-YAG laser were reported by other investigators [13].

The microstructures of HAZs produced in the three cases of treatment; $700 \mathrm{~W}, 1000$ and $1500 \mathrm{~W}$ are shown in figures 7,8 and 9 respectively. Figures 8 (c \& d) show the SEM images for the microstructure of the HAZ produced in the case of processing power of $1000 \mathrm{~W}$. Graphite nodules are found in the microstructure. Due to the high specific heat of graphite [16], a large amount of heat is accumulated in it during heating. According to the temperature at the graphite nodules and the resulting cooling rates, either retained austenite (or ledeburite: austenite and cementite) or martensite can be formed as a shell around the nodules. Martensitic structure can be observed in the HAZ. To specify the different phases produced in this zone, additional analyses for elements and phases with the aids of EDX and XRD are required. The formation of ledeburite as a shell around the graphite nodules and the transformation of austenite, which produced besides the ledeburite, into martensite with retained austenite were confirmed in studies by other investigators in the case of pearlitic-ferritic nodular iron 400-12 treated by Nd: YAG laser with $12 \mathrm{~J}$ output power, $4 \mathrm{~Hz}$ frequency of pulses and beam travelling speed of $330 \mathrm{~mm} / \mathrm{min}$. [16]. The occurrence of martensite shells or ledeburite ones around the graphite nodules in the ferrite matrix was also analyzed by other investigators for the same nodular iron (400-12) treated by $\mathrm{CO}_{2}$ laser with power of $450 \mathrm{~W}$ at beam travelling speed of $720 \mathrm{~mm} / \mathrm{min}$. [17]. 
In the three conditions of the present treatment $(700,1000$ and $1500 \mathrm{~W})$, no crack was observed in the two zones; melted and solidified zone and the HAZ. Components of small thickness; $6 \mathrm{~mm}$; and width; $50 \mathrm{~mm}$; were used as specimens in this study. In this case, no considerable effect for the internal thermal stresses is resulted.

\section{Effect of Treatment on the Hardness}

In the melted and solidified zone, the new structure of very fine austenite containing high percentage of carbon, cementite and martensite produces hard surface layers of high hardness as shown in Fig. 10. Remarkable improvements in hardness of the treated layer; ranged from 420 to $470 \%$; were achieved. The depth of melted zone increases by the increase of processing power. Accordingly, the depth of the hardest layer, produced from the melting and rapid solidification, increases by the increase of the processing power. The maximum melted depths for the hardest layers are 0.8 , 1.2 and $1.4 \mathrm{~mm}$ in the cases of 700,1000 and $1500 \mathrm{~W}$ respectively. The increase of surface hardness for nodular cast iron due to the melting by laser is also reported by other investigators [14].

In the heat affected zone, the high percentage of martensitic structure and the probable modified ledeburite (retained austenite containing high percentage of carbon and cementite) or martensite around the graphite nodules increase the hardness of this zone. As a result and as shown in Fig. 10, hardness distribution along the depth of the melted and heat affected zones is obtained.

\section{CONCLUSIONS}

The results of the present study lead to the following conclusions:

1. The laser surface melting treatments using $\mathrm{CO}_{2}$ laser with processing powers of 700,1000 and $1500 \mathrm{~W}$ at beam travelling speed of $500 \mathrm{~mm} / \mathrm{min}$. can be considered as effective treatments for modifying and hardening of surface for the nodular iron used in this study.

2. The application of this treatment lead to production of three main zones: the melted and solidified zone, heat affected one (HAZ) and the base metal. In the melted and solidified zone, high percentages of graphite nodules are completely dissolved and fine dendrites of austenite surrounded by cementite and some martensite are produced. Graphite nodules and martensitic structure can be produced in the HAZ.

3. Sound and hardened zones (melted and HAZ without cracks) can be produced in the three conditions of treatment.

4. The hardest layers can be produced by the laser surface melting and solidification. For these layers, remarkable improvements (420-470\%) in microhardness values can be achieved. The depths of these layers increase with the increase of processing power. Hard layers, produced by melting and 
solidification, of $0.8,1.2$ and $1.4 \mathrm{~mm}$ depths can be obtained at processing powers of 700,1000 and $1500 \mathrm{~W}$, respectively.

5. Heat affected zone (HAZ) of high hardness can be produced.

\section{ACKNOWLEDGEMENTS}

The author wishes to express his great thanks to the staff members of Central Metallurgical Research \& Development Institute (CMRDI), Cairo, Egypt, for their help and support in the preparation of the samples and conducting the laser treatments.

\section{REFERENCES}

[1] Y. Kayali, S. Taktak, S. Ulu and Y. Yalcin, "Investigation of Mechanical Properties of Boro-Tempered Ductile Iron", Materials and Design 31, 17991803, (2010).

[2] M. N. Ahmadabadi and R. Shamloo, "Control of Austenitic Transformation In Ductile Iron Added by Calculation of Fe-C-Si-X Phase Boundaries", J Phase Equilib 22, 194-198, (2001).

[3] R. A. Jeshvaghani, M. Jaberzadeh, H. Zohdi and M. Shamanian, " Microstructural Study and Wear Behavior of Ductile Iron Surface Alloyed by Inconel 617", Materials and Design, Accepted Manuscript, (2013).

[4] P. Chaengkham and P. Srichandr, "Continuously Cast Ductile Iron: Processing, Structures, and Properties", Journal of Materials Processing Technology 211, 1372-1378, (2011).

[5] H. Yan, A. Wang, Zh. Xiong, Ka. Xu and Z. Huang, "Microstructure and Wear Resistance of Composite Layers on A Ductile Iron with Multicarbide by Laser Surface Alloying", Applied Surface Science 256, 7001-7009, (2010).

[6] R. A. Jeshvani, E. Harati and M. Shamanian, "Effect of Surface Alloying on Microstructure and Wear Behavior of Ductile Iron Surface-Modified with A Nickel Based Alloy Using Shielded Metal Arc Welding", Materials \& Design 32, 1531-1536, (2011).

[7] A. Gulzar, J.I. Akhter, M. Ahmad, G. Ali, M. Mahmood and M. Ajmal, "Microstructure Evolution during Surface Alloying of Ductile Iron and Austempered Ductile Iron by Electron Beam Melting", Applied Surface Science 255, 8527-8532, (2009).

[8] Y. Sahin and O. Durak, "Abrasive Wear Behaviour of Austempered Ductile Iron", Mater Des 28, 1844-1850, (2007).

[9] M.B. Karamıs and K. Yıldızlı, "Surface Modification of Nodular Cast Iron: A Comparative Study on Graphite Elimination", Materials Science and Engineering A 527, 5225-5229, (2010).

[10] M. Eroglu and N. Ozdemir, "Tungsten-Inert Gas Surface Alloying of A Low Carbon Steel", Surface and Coatings Technology 154, 209-217, (2002). 
[11] S.O. Yilmaz, "Wear Behavior of Gas Tungsten Arc Deposited FeCrC FeCrSi, and WCo Coatings on AISI 1018 Steel", Surface and Coatings Technology 194, 175-183, (2005).

[12] M. Ahmad, M.A. Haq, E. Ahmeda, G. Ali, J.I. Akhter and M. lqbal, "Microstructure and Hardness Studies of Electron Beam Melted Surface of Mild Steel", Applied Surface Science 255, 6721-6723, (2009).

[13] A. Fernandez-Vicente, M. Pellizzari and J.L. Arias, "Feasibility of Laser Surface Treatment of Pearlitic and Bainitic Ductile Irons for Hot Rolls", Journal of Materials Processing Technology 212, 989-1002, (2012).

[14] K.Y. Benyounis, O.M.A. Fakron, J.H. Abboud, A.G. Olabi and M.J.S. Hashmi, "Surface Melting of Nodular Cast Iron by Nd-YAG Laser and TIG", Journal of Materials Processing Technology 170, 127-132, (2005).

[15] K.F. Alabeedi, J.H. Abboud and K.Y. Benyounis, "Microstructure and Erosion Resistance Enhancement of Nodular Cast Iron by Laser Melting", Wear 266, 925-933, (2009).

[16] Y. Chen, C.H. Gan, L.X. Wang, G. Yu, and A. Kaplan, "Laser Surface Modified Ductile Iron by Pulsed Nd: YAG Laser Beam with Two-dimensional Array Distribution", Applied Surface Science 245, 316-321, (2005).

[17] J. Gum and R. Sturm, "Comparison of Measured and Calculated Thickness of Martensite and Ledeburite Shells Around Graphite Nodules in the Hardened Layer of Nodular Iron after Laser Surface Remelting", Applied Surface Science 187, 116-123, (2002). 

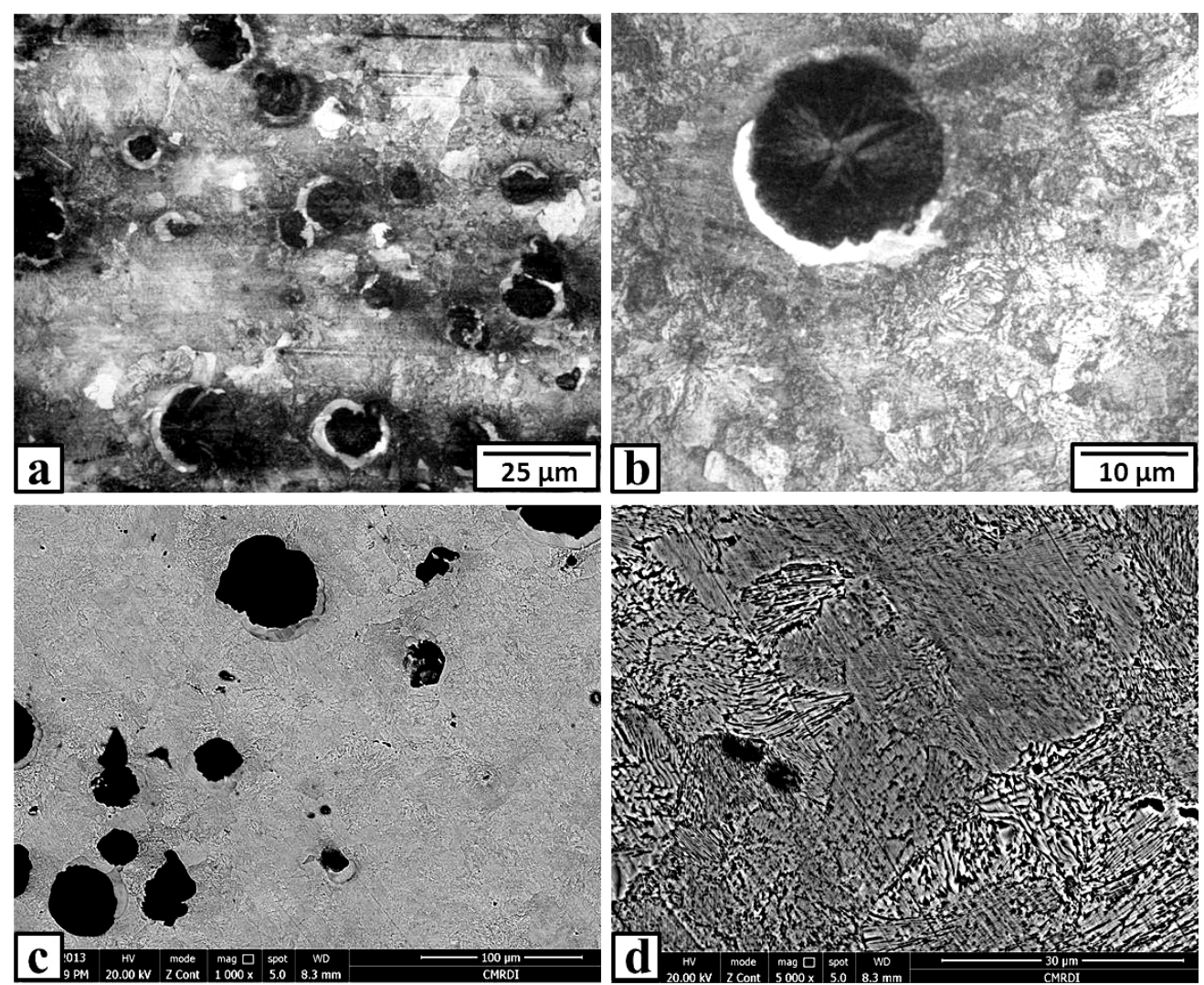

Fig. 1. Optical micrographs (a); X200 and (b); X500; and SEM images (c) and (d) for microstructure of the base metal (nodular cast iron).

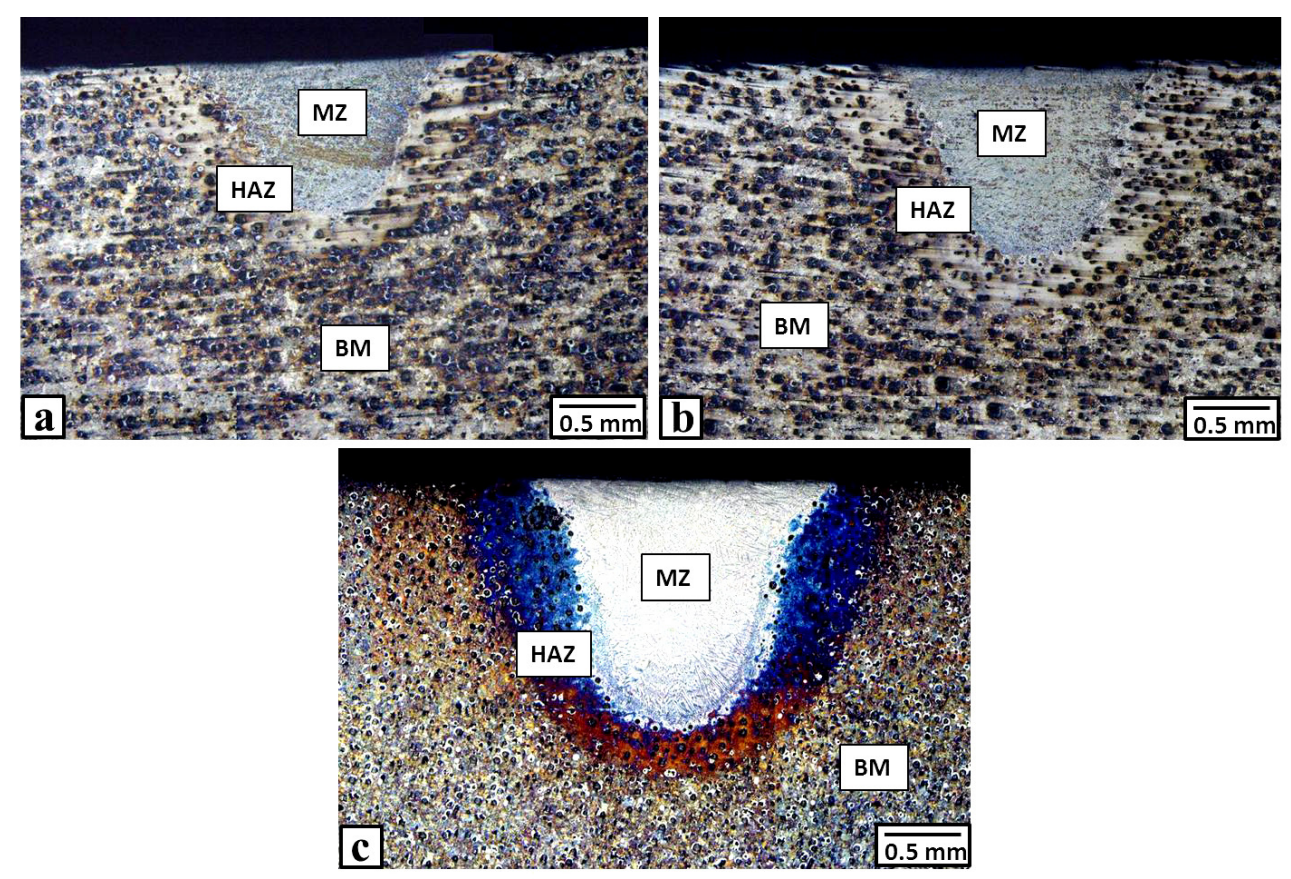

Fig. 2. Optical macrographs for the macrostructures of zones produced after application of laser surface melting at beam traveling speed of 500 $\mathrm{mm} / \mathrm{min}$. and power of $700 \mathrm{~W}(\mathrm{a}), 1000 \mathrm{~W}(\mathrm{~b})$ and $1500 \mathrm{~W}$ (c) 

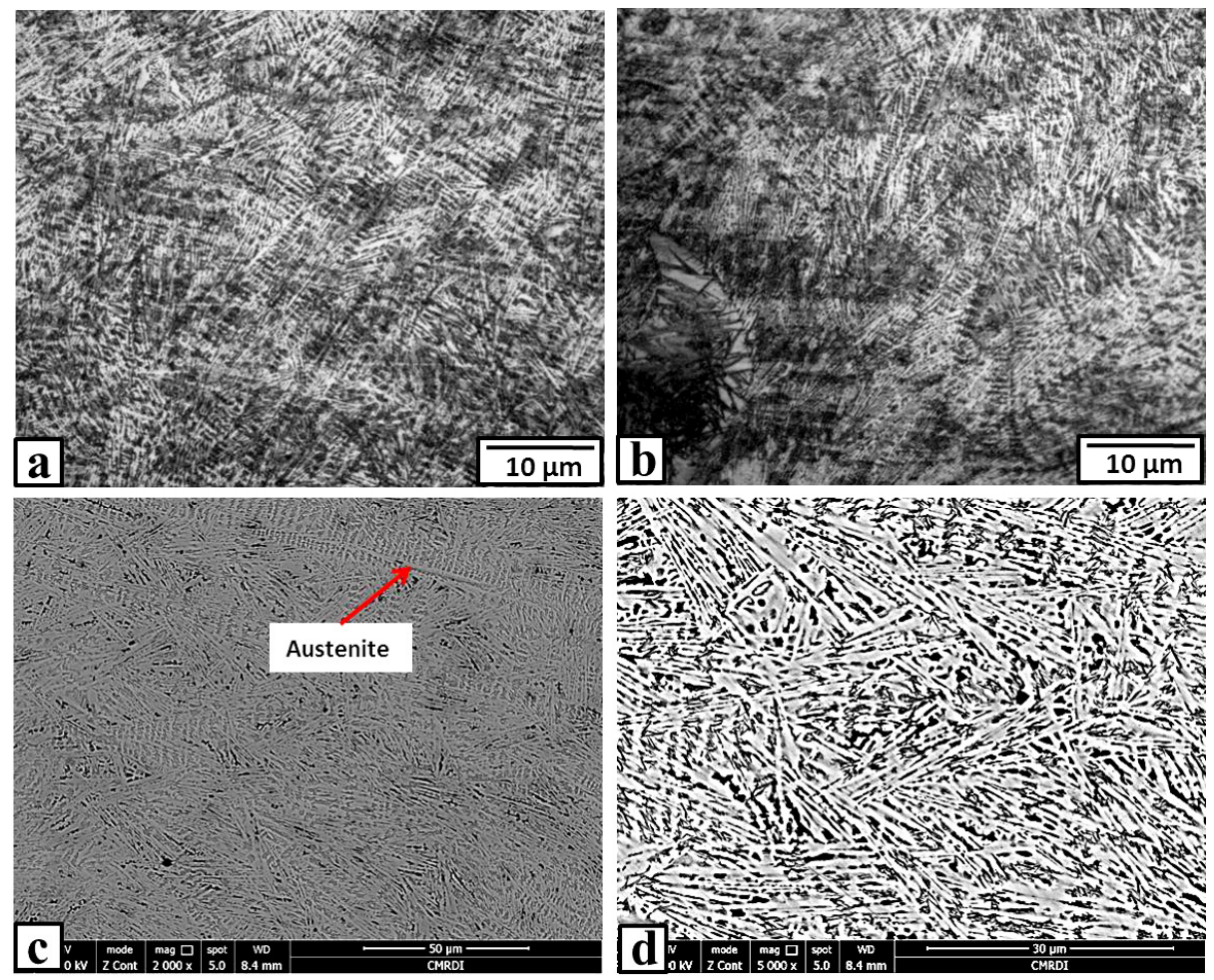

Fig. 3. Optical micrographs (a); X500 and (b); X500; and SEM images (c) and (d) for microstructure of the melted and solidified zone produced at power of $700 \mathrm{~W}$ and traveling speed of $500 \mathrm{~mm} / \mathrm{min}$.
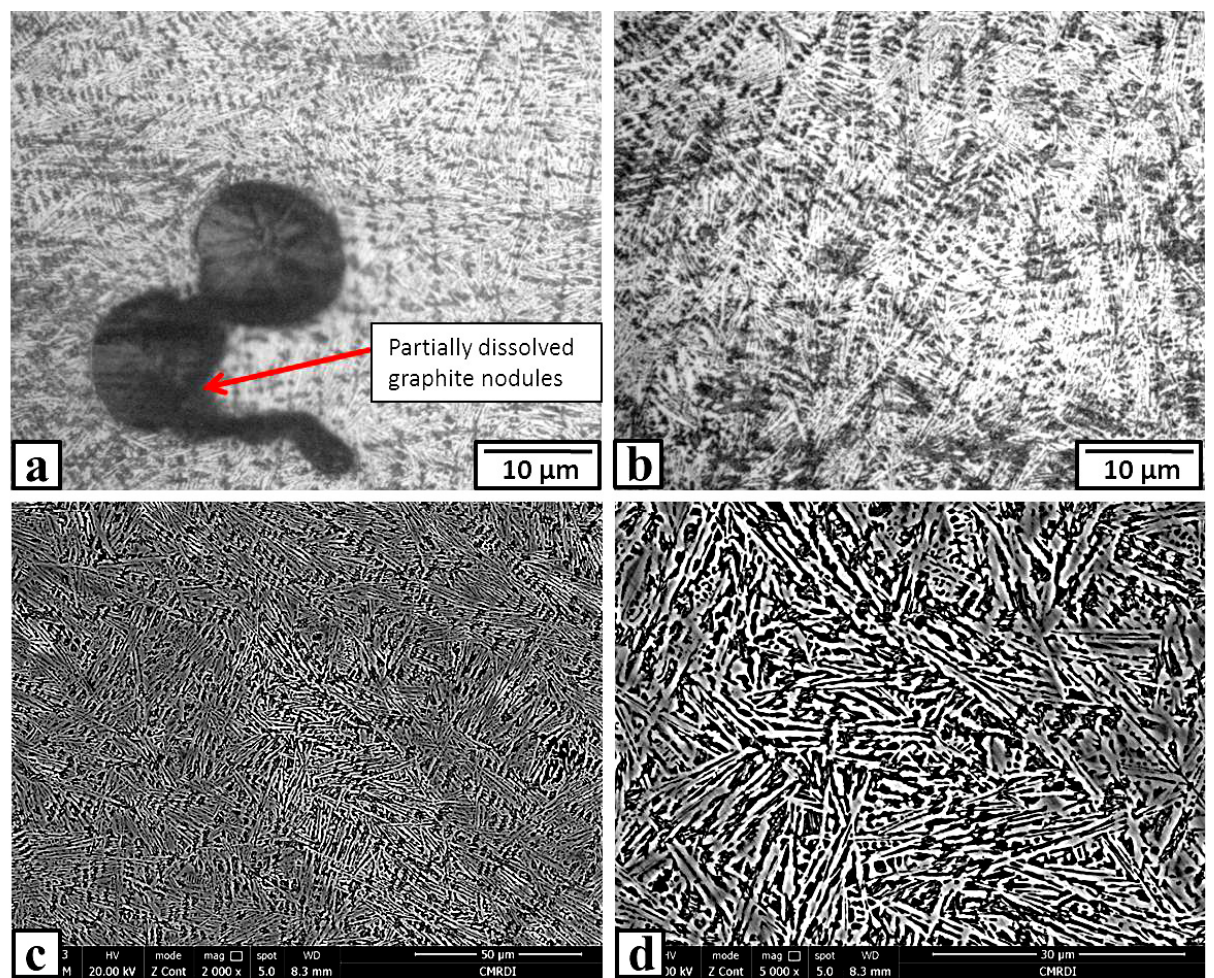

Fig. 4. Optical micrographs (a); X500 and (b); X500; and SEM images (c) and (d) for microstructure of the melted and solidified zone produced at power of 1000 $\mathrm{W}$ and travelling speed of $500 \mathrm{~mm} / \mathrm{min}$. 

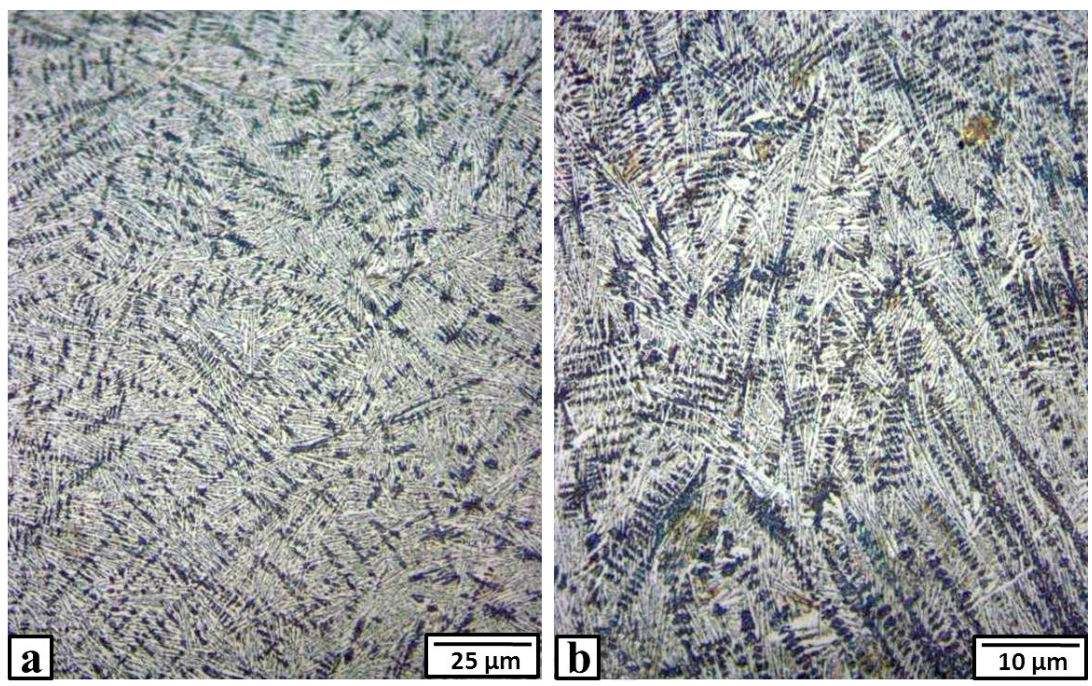

Fig. 5. Optical micrographs (a); X200 and (b); X500; for microstructure of the melted and solidified zone produced at power of $1500 \mathrm{~W}$ and traveling speed of 500 $\mathrm{mm} / \mathrm{min}$.
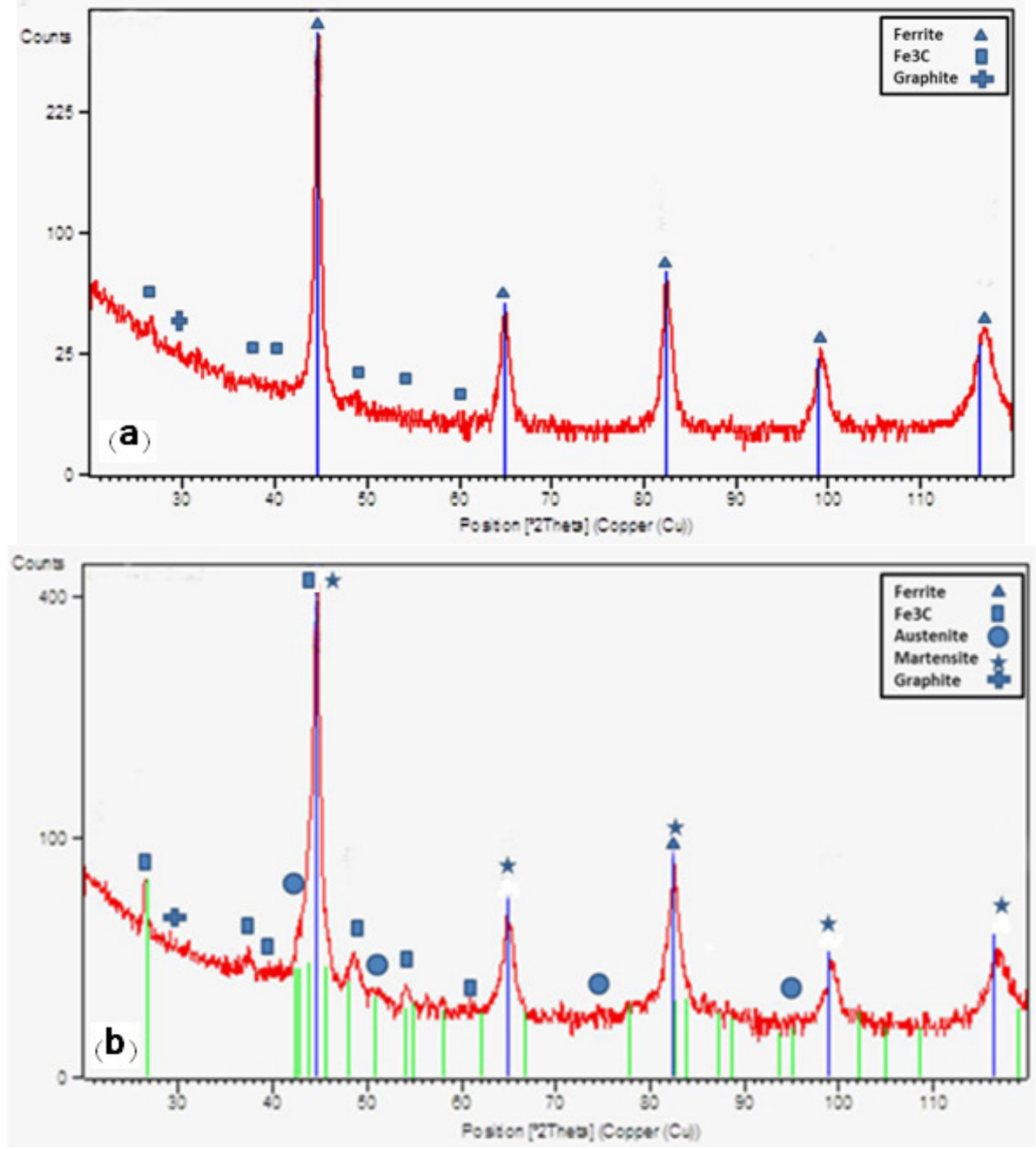

Fig. 6. X-ray diffraction pattern taken from surface of nodular cast iron. (a) before laser surface melting and (b) after laser surface melting (1000 W and traveling speed of $500 \mathrm{~mm} / \mathrm{min}$ ). 


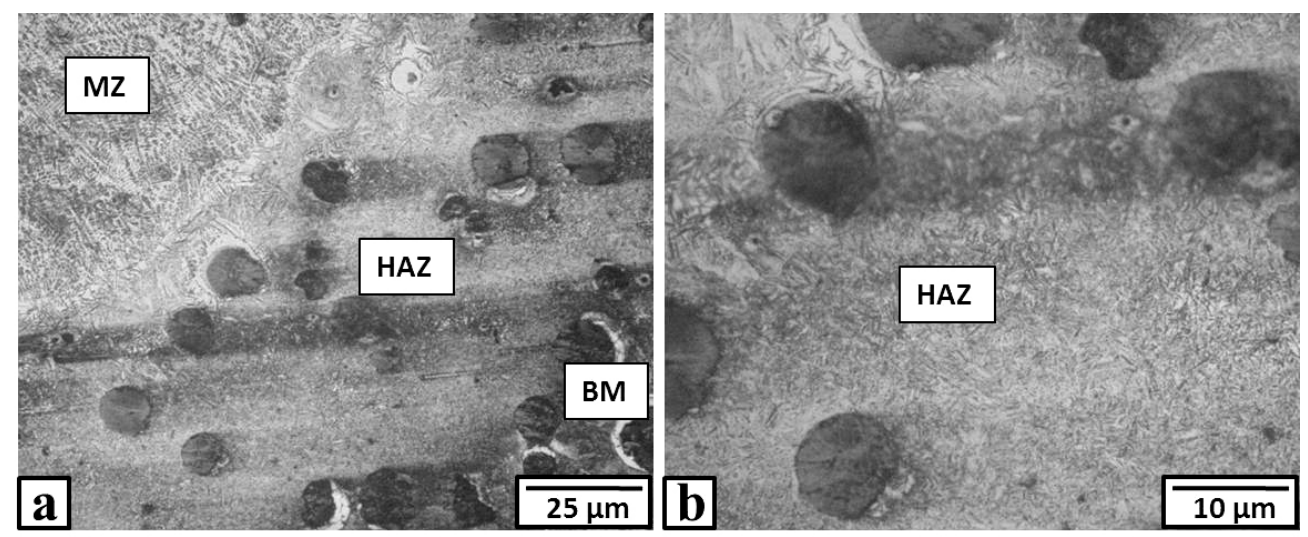

Fig. 7. Optical micrographs (a); X200 and (b); X500; for microstructure of the heat affected zone (HAZ) produced at power of $700 \mathrm{~W}$ and traveling speed of $500 \mathrm{~mm} / \mathrm{min}$. Portions of $\mathrm{MZ}$ and BM are shown in (a).
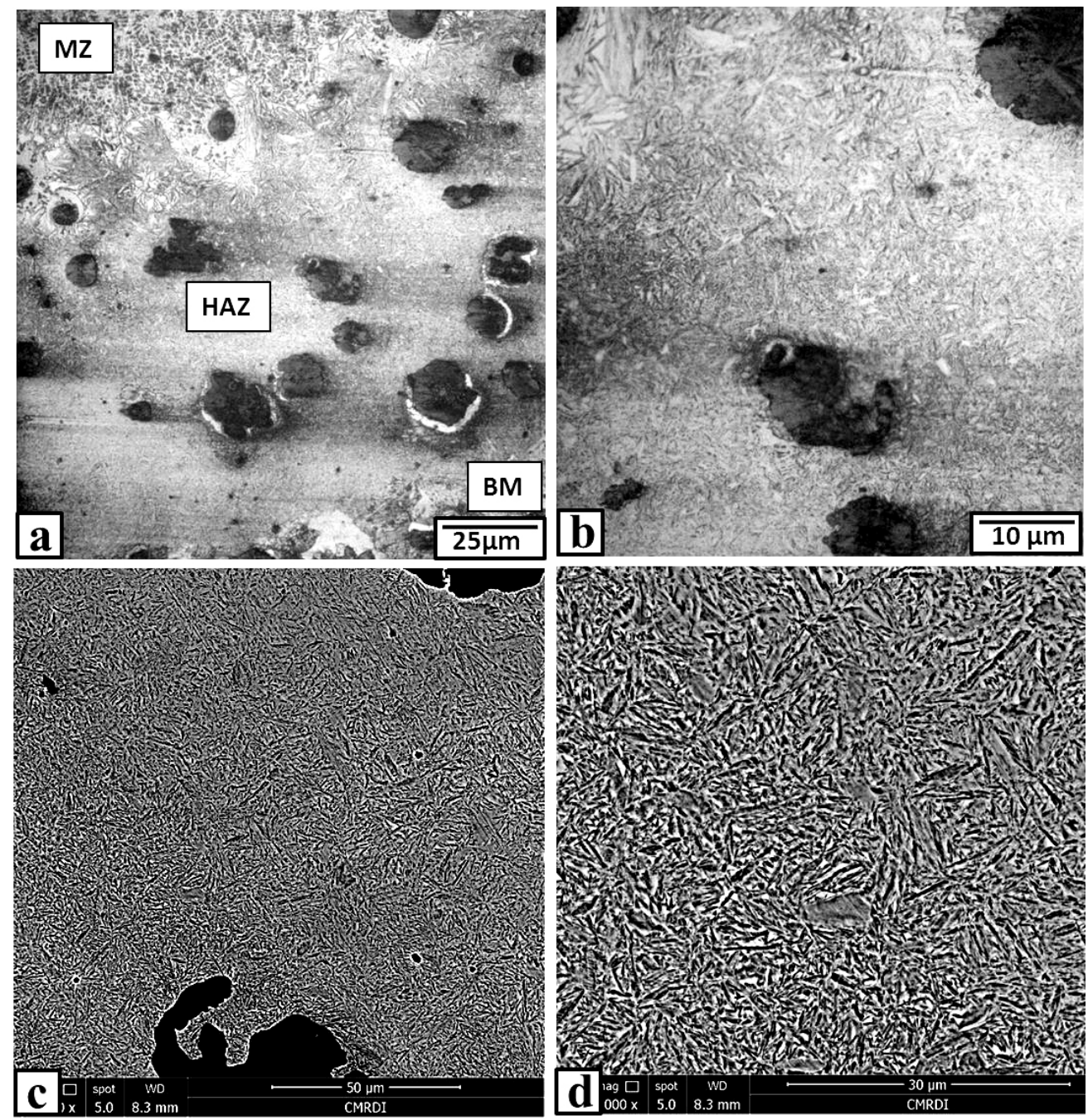

Fig. 8. Optical micrographs (a); X200 and (b); X500; and SEM images (c) and (d) for microstructure of the heat affected zone (HAZ) produced at power of $1000 \mathrm{~W}$ and traveling speed of $500 \mathrm{~mm} / \mathrm{min}$. Portions of $\mathrm{MZ}$ and $\mathrm{BM}$ are shown in (a). 

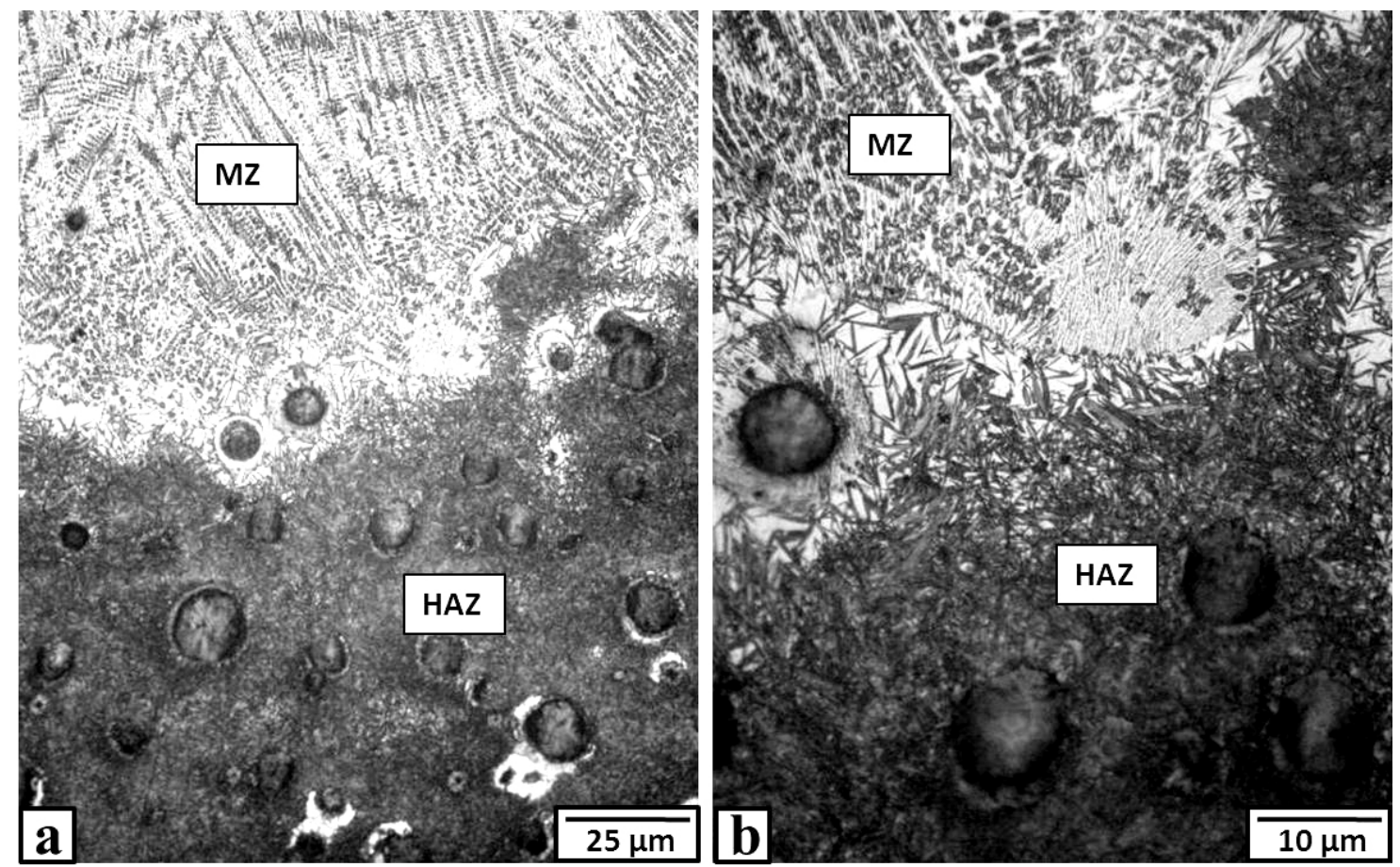

Fig. 9. Optical micrographs (a); X200 and (b); X500; for microstructures of the melted (MZ) and heat affected zones (HAZ) produced at power of $1500 \mathrm{~W}$ and traveling speed of $500 \mathrm{~mm} / \mathrm{min}$.

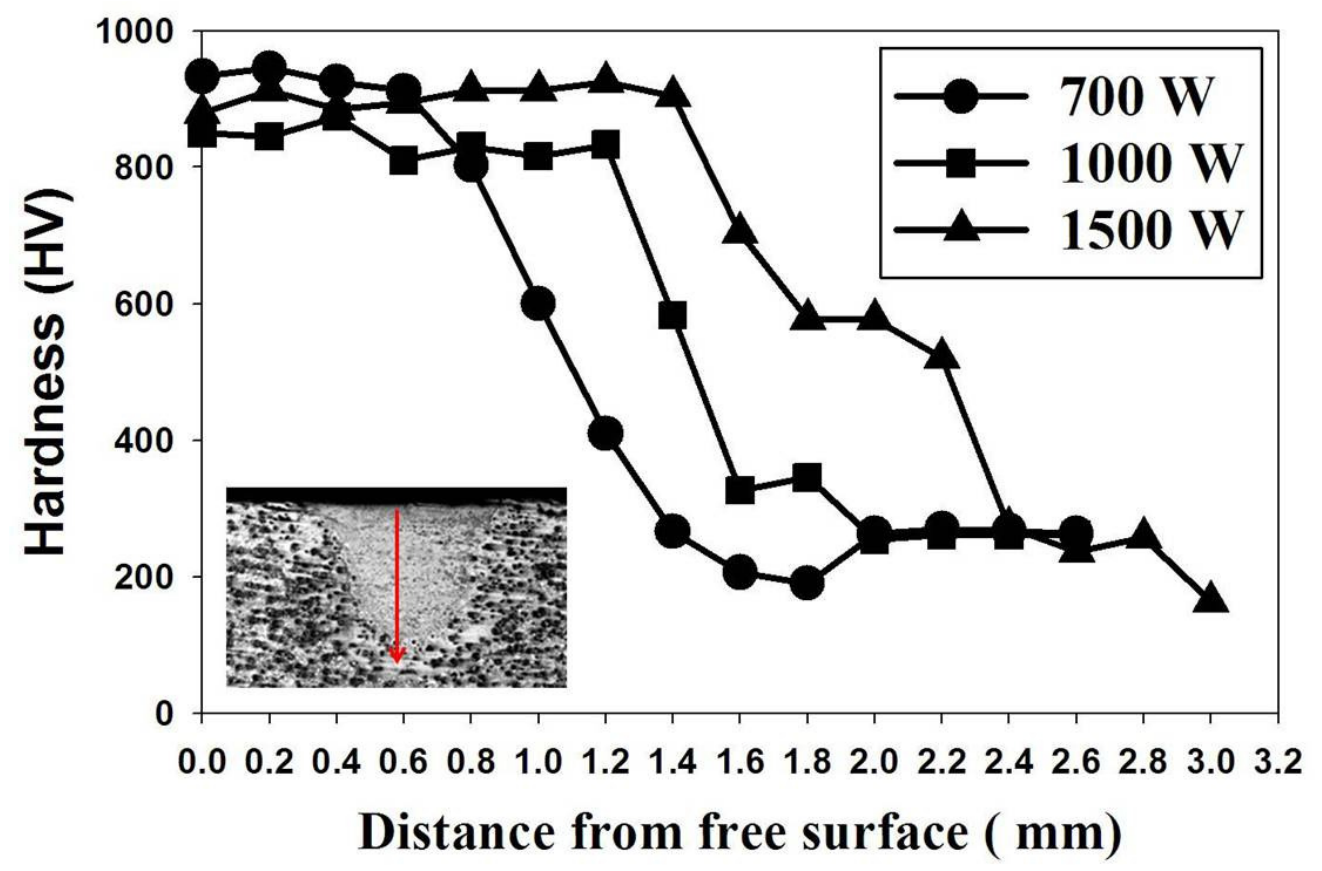

Fig. 10. Effect of processing power on hardness along depth for the travel speed of $500 \mathrm{~mm} / \mathrm{min}$. The Load used and loading time were $9.8 \mathrm{~N}$ and $15 \mathrm{sec}$ respectively. 